\title{
Eco-friendly composites for brake pads from agro waste: a review
}

\begin{abstract}
Natural fibers possess unique property densities that make them potential alternative reinforcement materials in synthetic brake pad composites. This article presents a comprehensive review for the potential and possibilities of reinforcing brake pads using natural plant-based fibers. The influential keys to designing brake pad composites are found to be thermal stability, interfacial bond of the matrix with the fiber, thermal fade, effectiveness, and recovery. Besides that, the optimization technique for manufacturing process of eco-friendly brake pads is also covered. It can be concluded that natural fibers can be used as potential materials for designing effective eco-friendly brake pad composites in the near future.
\end{abstract}

Keyword: Brake pad composites; Friction; Mechanical properties; Natural fibers; Tribological properties; Wear 